\title{
A Functional Anatomical Study of Unipolar Depression
}

\author{
Wayne C. Drevets, ${ }^{1}$ Tom O. Videen, ${ }^{2}$ Joseph L. Price, ${ }^{3}$ Sheldon H. Preskorn, ${ }^{6}$ S. Thomas Carmichael, ${ }^{3}$ and \\ Marcus E. Raichle $e^{2,45}$ \\ Departments of ${ }^{1}$ Psychiatry, ${ }^{2}$ Neurology and Neurological Surgen (Neurology), and ${ }^{3}$ Anatomy and Neurobiology, ${ }^{4}$ Division \\ of Radiation Sciences, Mallinckrodt Institute of Radiology, and ${ }^{5}$ the McDonnell Center for the Studies of Higher Brain \\ Function, Washington University School of Medicine, St. Louis, Missouri 63110 and ${ }^{6}$ Department of Psychiatry, University \\ of Kansas School of Medicine-Wichita, Wichita, Kansas 64214
}

The functional neuroanatomy of unipolar major depression was investigated using positron emission tomography to measure differences in regional cerebral blood flow (BF). A relatively homogeneous subject group was obtained using criteria for familial pure depressive disease (FPDD), which are based upon family history as well as upon symptoms and course. Because of the absence of certain knowledge about the pathophysiology of mood disorders and their underlying functional neuroanatomy, we used data obtained from the subtraction of composite images from one-half of depressed and control subjects to identify candidate regions of interest. The major cortical region defined in this manner was statistically tested on a second set of subjects. Using this strategy, we found increased BF in an area that extended from the left ventrolateral prefrontal cortex onto the medial prefrontal cortical surface. Based upon the connectivity between these portions of the prefrontal cortex and the amygdala and evidence that the amygdala is involved in emotional modulation, activity was measured in the left amygdala and found to be significantly increased in the depressed group. A separate group of subjects with FPDD who were currently asymptomatic were also imaged to determine whether these findings represented abnormalities associated with the depressed state, or with a trait difference that might underlie the tendency to become depressed. Only the depressed group had increased activity in the left prefrontal cortex, suggesting that this abnormality represents a state marker of FPDD. Both the depressed and the remitted groups demonstrated increased activity in the left amygdala, though this difference achieved significance only in the depressed group. This suggests that the abnormality involving the left amygdala may represent a trait marker of FPDD, though further assessment in a larger sample size is necessary to establish this. These data along with other evidence suggest that a circuit involving the prefrontal cortex, amygdala, and related parts of the striatum, pallidum, and medial thalamus is involved in the functional neuroanatomy of depression.

\footnotetext{
Received Dec. 9, 1991; revised Apr. 3, 1992; accepted Apr. 15, 1992.

We thank the staff of the division of Radiation Sciences for technical assistance, and Edward Spitznagel, Ph.D., for statistical advice. This work was supported by NIH Grants HL 13851 and NS 06833 and by the MacArthur Foundation.

Correspondence should be addressed to Wayne C. Drevets, M.D., Department of Psychiatry, Washington University School of Medicine, 4940 Audubon, St. Louis, MO 63110.

Copyright (C) 1992 Society for Neuroscience $0270-6474 / 92 / 123628-14 \$ 05.00 / 0$
}

Major depression rivals hypertension as the most frequent illness encountered in primary health care settings (Schwenk and Coyne, 1990). It is also the most significant precursor of suicide, being recognized in approximately half of completed suicides (Murphy, 1986), and is associated with excess mortality from cardiovascular disease and accidental death (Rush et al., 1991). Morbidity resulting from this disorder includes substantial suffering, disability, and social impairment.

The diagnosis of primary major depression is based upon the presence of the major depressive syndrome and the absence of other medical or psychiatric illnesses that might be associated with it (e.g., Parkinson's disease or schizophrenia) (Winokur, 1986). The major depressive syndrome consists of a pathologic disturbance of mood and affect in which a persistent negative emotional state is accompanied by changes in energy, sleep, appetite, activity, and cognition (American Psychiatric Association, 1987). Rather than simply consisting of sadness, the mood change may be described as an emotional "pain," an inability to experience pleasure (anhedonia), or persistent anxiety. Depression's cognitive features include persistent ruminations of guilt, death, failure, inadequacy, personal loss, or self destruction. Differing from normally reactive low mood, the major depressive syndrome does not simply arise in response to medical or psychosocial stressors (Craig, 1986; Goodwin and Jamison, 1990; Kathol et al., 1990).

Increasing evidence suggests but does not define a neurobiologic basis for major depression (Goodwin and Jamison, 1990; Rush et al., 1991). This evidence includes genetic factors (Rush et al., 1991), neurochemical abnormalities (Meltzer, 1987), neuroendocrine disturbances (Meltzer, 1987; Goodwin and Jamison, 1990; Rush et al., 1991), neuropsychological impairments (Sackeim and Steif, 1988), and abnormalities in circadian rhythms and sleep stages. Thus, major depression may involve several neural systems within the brain. However, because primary major depression is not associated with abnormalities of brain structure, its neuroanatomical correlates have remained unclear.

Positron emission tomography (PET) holds particular promise as a tool to delineate the functional anatomy of major depression. By tomographically measuring blood flow (BF) or metabolism, PET produces a three-dimensional picture of regional synaptic activity associated with either normal physiologic activity or disease states (Raichle, 1987). Since mood disorders are characterized by episodes of illness followed by return to the premorbid baseline (Goodwin and Guze, 1984), PET affords 
the ability to distinguish state-related differences (present only when symptomatic) from trait differences (present whether symptomatic or asymptomatic) by imaging subjects during the depressed and remitted phases, respectively.

However, investigating major depression is complicated by the probability that this syndrome encompasses a heterogeneous group of disorders (Winokur, 1982, 1986). Presence of the syndrome is established by a history of symptoms or behaviors that are subject to patient or clinician interpretation, rather than by objective biolugical markers. The biological abnormalities mentioned above have typically been present only in subgroups of subjects meeting clinical criteria for major depression. Such observations suggest that major depression is probably associated with multiple pathophysiologic states and may thus be associated with an assortment of different PET images. Some means of selecting a homogeneous subject group is therefore essential to detect physiologic differences sensitively between depressed and control groups.

The clearest categorical distinction within major depression exists between unipolar and bipolar depression (bipolar subjects experience manic as well as depressive episodes). Unipolar and bipolar depression appear to be neurochemically, pharmacologically, physiologically, and genetically distinct (Baxter et al., 1985, 1989; Rice et al., 1987; Schwartz et al., 1987, 1989; Schatzberg et al., 1989; Goodwin and Jamison, 1990; Moldin et al., 1991). Within unipolar depression, additional heterogeneity appears to exist, although controversy remains as to subdivisions therein (Lewis, 1971; Zimmerman et al., 1990). One classification for unipolar depression capitalizes on the heritability of affective disorders, and identifies three subtypes based upon family history: depressive spectrum disease, familial pure depressive disease (FPDD), and sporadic depressive disease (Winokur, 1982). Of the three, FPDD is most consistently associated with biologic markers for affective illness (Winokur, 1982). FPDD is defined as primary major depression in an individual who has a first-degree relative (parent, sibling, or offspring) with primary depression but no family history of alcoholism, antisocial personality, or mania. We have attempted to obtain a homogeneous sample of unipolar major depressives for study with PET by selecting subjects with FPDD. Our objective was to search for the functional anatomical features that characterize both the disease and the clinical state of depression.

\section{Materials and Methods}

Three subject groups were selected: a group with FPDD who were currently depressed, a group with a history of the same disorder who were in remission (asymptomatic) at the time of study, and a group of controls. All subjects were right-handed as determined by the Edinburgh handedness inventory (Raczkowski, 1974). All subjects were free of any medical or neurological disorders or medications likely to affect cerebral $\mathrm{BF}$. Informed consent was obtained after the nature and possible consequences of the study were explained.

Thirteen subjects were selected who had primary affective disorder, met DSM III-R criteria for major depression (American Psychiatric Association, 1987), and had followed a unipolar course, as determined by both an unstructured interview with a psychiatrist (W.C.D. or S.H.P.) and a structured interview (the DIS; Robins et al., 1989). Subjects had never met criteria for any other psychiatric disorder, and had first-degree relatives with a history of unipolar major depression according to DSM III-R criteria, but not mania, alcoholism, or antisocial personality disorder (i.e., criteria for FPDD were satisfied; Winokur, 1982). In addition, all subjects met DSM III-R criteria for "recurrent" course (multiple episodes separated by return to usual functioning) and "melancholic type." Hamilton Depression Rating Scale (HDRS) scores (21 items; Hamilton, 1960) were in the moderate to severely depressed range [mean score, $27.3 \pm 4.6$; range, $21-35$, with the upper limit of normal being a score of 7 (Bech et al., 1986)]. Mean age was $36.2 \pm 8.9$ years (range, $22-52$ years); $54 \%$ were female. Subjects had been unmedicated for at least 3 weeks, and four of the subjects had never received psychotropic medication. For the nine subjects who had previously received psychotropic medications, the mean drug-free period was $7.5 \pm 9.6$ months (range, 3 weeks to 2 years). Subjects were not withdrawn from medication for the purposes of this study. Associated clinical features included secondary obsessions in one subject, psychotic features in one subject, and panic attacks in two subjects. These are typical incidences of such symptoms in unipolar major depression (Winokur, 1986), and in each case these symptoms were clearly secondary to the primary mood disorder (Goodwin and Guze, 1984).

An additional 10 subjects were selected who had met the same criteria in the past (i.e., they had suffered recurrent, unipolar major depressive episodes and met criteria for FPDD) but had been asymptomatic (in remission) and unmedicated for at least 4 months prior to imaging. Subjects were judged to be clinically euthymic and had HDRS scores in the nondepressed range at the time of scanning. The mean duration of remission was $2.3+2.2$ years (range, 4 months to 7 years). Six of the subjects had never received psychotropic medications. For the four who had, the drug-free period ranged from 4 months to 13 years. Mean age was $33.6 \pm 10.0$ years (range, $24-55$ years), and $70 \%$ were female.

Control subjects $(n=33$; mean age, $30.1 \pm 7.8$ years; range, $22-50$ years; $61 \%$ female] matched for age, sex, and handedness were chosen for comparison with the patient group. Controls met the same exclusion criteria applied to the first two groups, but were free of any personal or family history of psychiatric illness, as determined by a structured and unstructured screening interview.

A $40 \mathrm{sec}$ PET scan was acquired for each subject following an intravenous bolus injection of $60-80 \mathrm{mCi}$ of $\mathrm{H}_{2}{ }^{15} \mathrm{O}$. Prior to scanning, subjects were instructed to close their eyes and relax without moving. (The eyes-closed, at-rest behavioral state is a stable and reproducible state, and is likely to demonstrate the baseline neurophysiologic correlates of the cognitive-behavioral and emotional set of depression. As such, it constitutes a reference point to which more specific cognitive-behavioral states or posttreatment states may be compared in future studies.) Image data were acquired with PETT VI (seven simultaneous slices with 14.4 $\mathrm{mm}$ center-to-center separation; Yamamoto et al., 1982). No attempt was made to position all subjects in the same fashion in the scanner relative to the PET slices. (In post hoc comparisons, we determined that no significant differences in positioning existed between patient and control sets as identified by slice markers on lateral skull radiographs.) Images were reconstructed to a transaxial resolution of $18 \mathrm{~mm}$ full width at half-maximum using filtered backprojection and measured attenuation.

Regional tissue radioactivity was measured, which over the range tested accurately reflects changes in regional cerebral BF due to the linear relationship between BF and radiation counts (Fox and Mintun, 1989). The use of radioactive counts rather than BF eliminates the need for artcrial cathetcrization. Wc cmployed this less invasive approach since we were interested in regional differences rather than global differences, and since previous studies had shown no differences in whole brain BF and metabolism between unmedicated, unipolar depressives and normals (Baxter et al., 1985; Drevets et al., 1989). To negate the effects of global fluctuations in activity, a linear normalization was applied to reconstructed images of radioactive counts by measuring the total counts within the brain and scaling all subjects to the same value.

Each subject's image was subsequently remapped into a common, stereotaxic, three-dimensional array with 49 slices comprised of $2 \mathrm{~mm}$ cubic voxels in which each voxel is located by its distance in three directions from the center of the bicommisural line (Talairach et al., 1967; Fox et al., 1985, 1987).

Empirical definition of a region of interest. Image data for the currently depressed and the control subjects were divided into two groups (distribution was random after stratification according to age and sex): group A, with six depressed subjects and 18 age- and sex-matched controls; and group $B$, with seven depressed subjects and 15 age- and sex-matched controls. Age and sex distribution for depressed subjects and controls in group $A$ was $37.3 \pm 9.3$ years $(67 \%$ female) and $30.3 \pm 7.4$ years (65\% female), respectively, and for group B, $35.3 \pm 9.1$ years $(57 \%$ female) and $29.9 \pm 8.0$ years $(60 \%$ female). An image consisting of unpaired $t$-values was created from group $A$ such that each voxel represented the mean difference in tissue radioactivity between the depressed and control subjects divided by the standard error of the dif- 

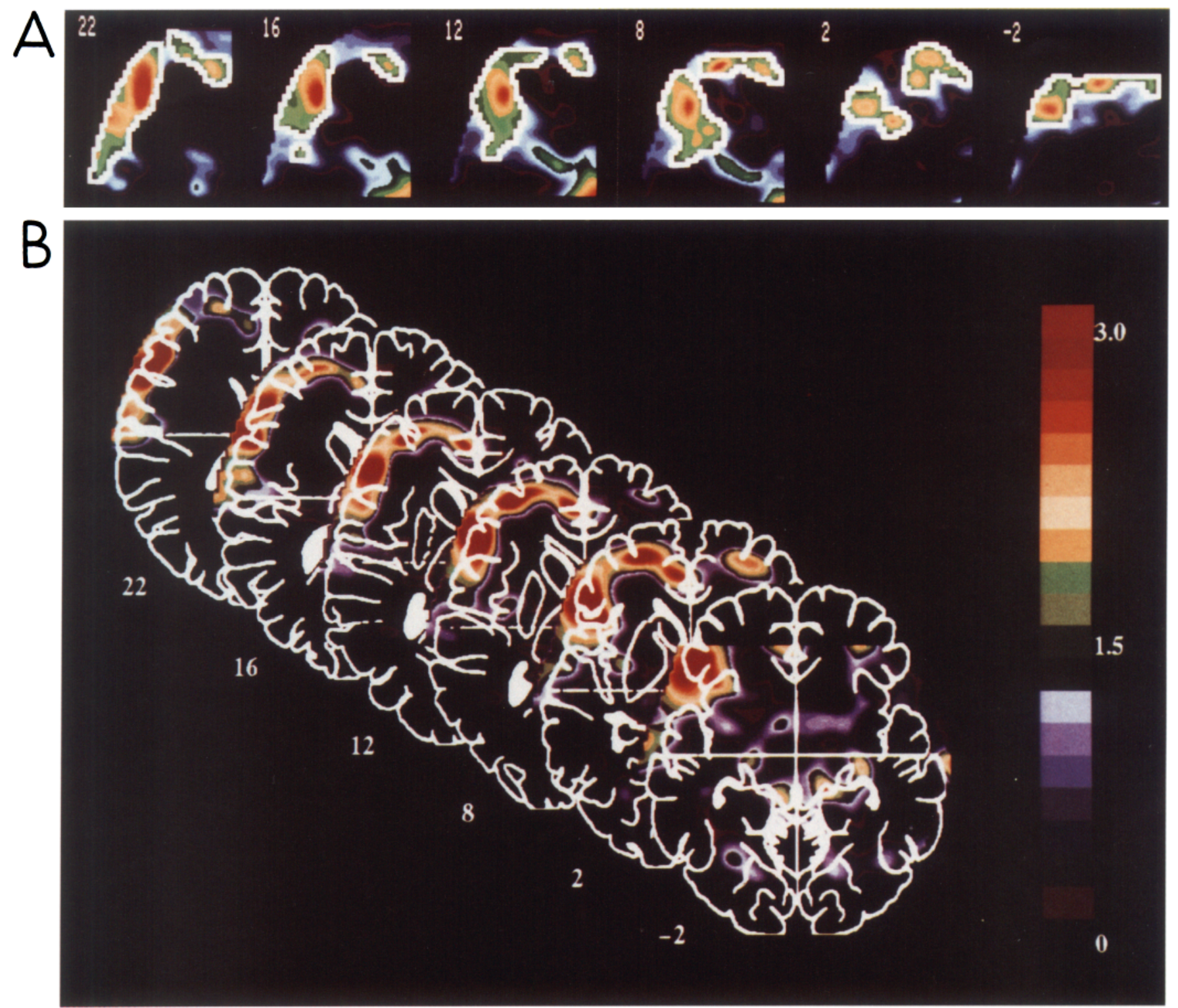

Figure 1. Extent of increased activity in the left prefrontal cortex of the depressed subjects. The horizontal t-image slices correspond to increased tissue radioactivity in the depressed relative to the control subjects. Image planes are located in millimeters from the bicommissural line by the number to the left of each slice (positive = superior). Left is toward the left, and anterior is toward the top; $x$ - and $y$-axes mark the center of the bicommissural line. $A$, The t-image sections shown were generated from the first half of the depressed and control subjects (group A). The VOI defined in the left prefrontal cortex is demarcated in white over the t-image planes. This VOI was drawn on isocontour levels in the t-image to encompass the largest positive peak in the data from subject group A, and to bound the surrounding area of positive voxel t-values in the left prefrontal cortex as illustrated. This represents an area where BF is increased in the depressed subjects from group A. The left anterior quadrant of each horizontal plane is demonstrated for comparison with the corresponding full image slices in $B$. $B$, Horizontal slices from the t-image created post hoc from all 13 depressives and 35 controls. These illustrate the extent of the left prefrontal cortical difference for the entire subject sample (sets $\mathrm{A}$ and $\mathrm{B}$ ), and may be compared with the corresponding differences in group $\mathrm{A}$ alone (in $A$ ). The t-image slices are overlaid on corresponding atlas section outlines (Talairach et al., 1967). No attempt was made to align the t-image and atlas outline edges (the stereotaxic transformation uses three orthogonal, linear scaling factors and does not attempt to match all brain boundaries to atlas edges). Increased activity in the left prefrontal cortex involved much of the VLPFC and extended through the tissue immediately caudal to the frontal pole to include part of the left medial prefrontal cortex (which includes the pregenual portion of the anterior cingulate gyrus).

ference (Fig. 1A). Each voxel was computed:

$$
t=\frac{\left(\mu_{2}-\mu_{1}\right)}{\sigma_{d}},
$$

where

$$
\sigma_{d}=\sqrt{\left(\sigma_{1}^{2} / n_{1}\right)+\left(\sigma_{2}^{2} / n_{2}\right)},
$$

with subscript 1 denoting controls and subscript 2 denoting depressed subjects. The t-image revealed those voxels whose activity differed most between the depressed and control subjects relative to each voxel's inherent variability, thus minimizing artifacts due to nonspecific differences in anatomy, physiology, and image processing.

Image voxels outside the mean brain boundary or not sampled in all 46 images (i.e., in every depressed and control subject's image) were zeroed and excluded from the analyses. The brain boundary corresponds 
Table 1. Comparison of regional PET activity between depressives and normals for the left prefrontal cortex and the left amygdala

\begin{tabular}{|c|c|c|c|c|c|}
\hline \multirow[b]{2}{*}{ Region of interest } & \multicolumn{3}{|c|}{ Coordinates $(\mathrm{mm})$} & \multirow[b]{2}{*}{ Hypothesis set } & \multirow[b]{2}{*}{ Test set } \\
\hline & $x$ & $y$ & $z$ & & \\
\hline Left prefrontal cortex & 47 & 41 & 10 & $+8.2 \%(t=2.80)$ & $+5.1 \%(t=2.21 ; p<0.025)$ \\
\hline Left amygdala & 21 & 5 & -14 & NA & $+5.8 \%(t=2.60 ; p<0.05)$ \\
\hline
\end{tabular}

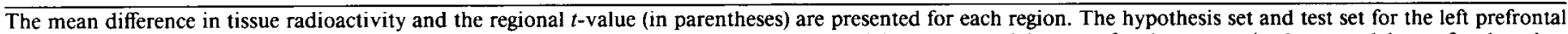

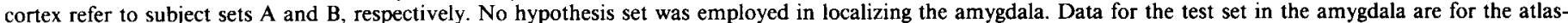

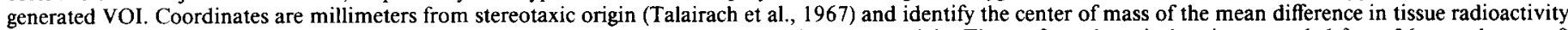

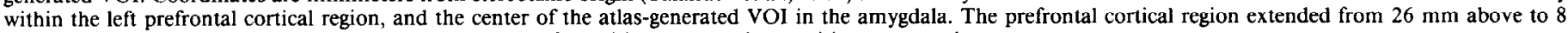
$\mathrm{mm}$ below the bicommissural line (Fig. 1). Positive $x=$ left; positive $y=$ anterior; positive $z=$ superior.

approximately to those pixels whose PET counts are $40 \%$ of the largest single pixel value across all slices. The mean brain boundary was thus defined by a $40 \%$ threshold applied to the mean flow image for all subjects. This served as an aid to automated volume-of-interest (VOI) definition (described below) by preventing regions from extending beyond the edges of the brain.

The largest difference between the depressives and controls in this first (hypothesis-generating) composite t-image was located in the left prefrontal cortex (Table 1). This highest voxel t-value $(t=4.10)$ was positive (corresponding to an area where BF in the depressives exceeded that of the controls) and was located within a large region of positive t-values (Fig. 1A). A large volume-of-interest (VOI) was defined to encompass this region of positive t-values within the left prefrontal cortex using computer-drawn boundaries based on three-dimensional isovalue contours (all pixels on the boundary had the identical pixel t-values) in the $t$-image from group A (Fig. $1 A$ ). The contour level was arbitrarily selected at a threshold of $33 \%$ of the peak $t$-value $(t=1.35)$ so that the VOI included not only the largest single pixel peak but two other local peaks, all in the left prefrontal cortex. A large volume was chosen to reduce the effects of unequal sampling in different subjects and of errors in transforming PET images of different subjects' brains to a common reference. The difference in mean activity and the value of $t$ was calculated for this entire region, and a power analysis was performed to assess the likelihood of replication using the sample sizes in group B.

We then tested the hypothesis that BF is elevated in this left prefrontal cortical region in the depressed state using subject group B. Normalized radioactivity (regional activity/global activity) was measured for this VOI in each of the depressed and control subjects in group B and compared using an unpaired $t$ test.

The amygdala as a region of interest. We next hypothesized that $\mathrm{BF}$ in the amygdala should also differ in the depressed subjects relative to the controls, based upon the extensive ipsilateral interconnectivity between the amygdala and the ventrolateral and medial prefrontal cortex (based upon experiments in monkeys; Amaral and Price, 1984) and the evidence that the amygdala is involved in emotional modulation (see Discussion). Only nine of the depressed subjects' scans included image planes ventral enough to sample the amygdala [the seven tomographic slices sample only $10 \mathrm{~cm}$ of brain (Yamamoto et al., 1982), which for some subjects did not extend ventrally to the amygdala], so division into two groups would have resulted in sample sizes too small to employ the two-step approach used to define and replicate the left prefrontal difference. Therefore, a spherical VOI comprising 25 voxels $(0.2 \mathrm{cc})$ was created using coordinates of the left amygdala from the Talairach atlas $[x=21 \mathrm{~mm}, y=5 \mathrm{~mm}, z=-14 \mathrm{~mm}$; Tablc 1 (Talairach ct al., 1967)]. This VOI was tested on all depressed $(n=9)$ and control $(n=27)$ subjects whose scans sampled the entire VOI (the mean age and sex distribution did not differ between these two subsets). Normalized activity was measured for each group and compared using an unpaired $t$ test.

Other regions. Other regions that appeared to have potential significance in group A were not assessed by comparison with group B. These peaks had smaller $t$-values and we chose not to test them, as even had they replicated at the $5 \%$ level, statistical corrections (Bonferroni) for multiple comparisons would have reduced the significance of all responses, including those in the left prefrontal cortex and the amygdala, below the customarily accepted level. However, in order to identify areas of probable BF difference that could guide hypotheses in FPDD, we created a composite t-image using the entire group of depressed ( $n$ $=13)$ and control $(n=33)$ subjects. This t-image was searched, voxel by voxel, with a computer program that identified the largest single voxel values to represent the largest local differences between the subject groups. Regions were defined at these local maxima, and regional tvalues were computed.

Post hoc analyses. Several post hoc comparisons were made to clarify the relationship between BF changes in these regions and (1) presence of the depressive syndrome, (2) changes in the same areas in the right hemisphere, and (3) severity of depression and anxiety. Total HDRS scores were employed as the measure of depression severity. For the measure of anxiety, summed scores for the HDRS items assessing psychic and somatic anxiety were used (Hamilton, 1967).

In the subjects whose depression was in remission, normalized radioactivity was measured for the left prefrontal VOI and compared to a subset of the controls $(n=22)$ that were age- and sex-matched with the remitted subjects (mean age, $30.2 \pm 7.3$ years; range, $21-49$ years; $67 \%$ female). Radioactivity in the left prefrontal region was also compared between the remitted subjects and the depressed subjects from group B (age and sex did not significantly differ between these two groups). Activity was also measured in the left amygdala for the remitted subjects whose image data extended ventrally to the amygdala $(n=8)$ and compared with the control $(n=22)$ and depressed subjects $(n=$ 9).

The laterality of these findings was assessed by measuring normalized activity in mirror-image VOIs located in the right hemisphere. The values for the right prefrontal and amygdala regions were compared with their homologous left-sided regions using paired $t$ tests. To evaluate the relationship between regional activity and age, depression severity, and anxiety, critical values of the Pearson product-moment correlation coefficient were calculated.

\section{Results}

\section{Prefrontal cortex}

After dividing the depressed and control subjects into two groups ( $A$ and $B$ ) for hypothesis generation and subsequent testing, the largest difference in the composite t-image from group $\mathrm{A}$ corresponded to an area of increased BF in the left prefrontal cortex of the depressives (Table 1). The VOI generated to encompass this region of positive $t$-values comprised 3155 voxels (approximately $25 \mathrm{cc}$ ), which contained much of the left ventrolateral prefrontal cortex (VLPFC) and extended through the tissue immediately caudal to the frontal pole to include part of the left medial prefrontal cortex (Fig. 1). A mean difference in normalized activity of $8.8 \%$ was found in this VOI between the depressed and control subjects from group $\mathrm{A}(t=2.80$, depressed $>$ control). Assuming that group A accurately reflected the population difference and the variability in both populations, an attempted replication with the sample sizes of group B with a one-tailed $t$ test with criterion $p \leq 0.05$ would have power $=$ 0.85 .

The hypothesis that BF was increased in this VOI in FPDD was confirmed using regional measurements from the second set of subjects. A mean increase in normalized activity of $5.1 \%$ was obtained in the depressed subjects relative to the controls from group B, with $t=2.21$ and $p<0.025$ ( $\mathrm{df}=20$, one-tailed; Table 1). 

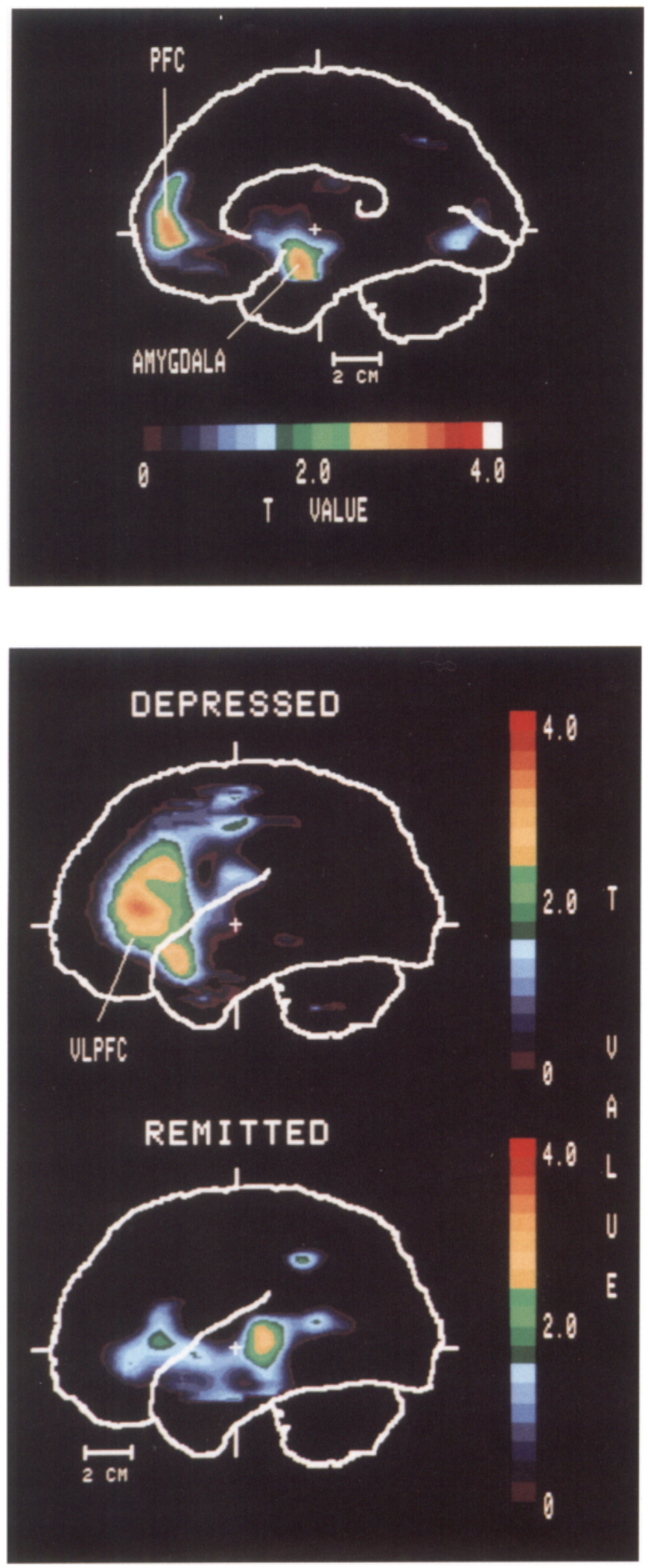

Figure 2. $\mathrm{t}$-image corresponding to increased $\mathrm{BF}$ in the depressives at the sagittal plane through the center of the amygdala $(21 \mathrm{~mm}$ left of midline). Anterior is toward the left. The $z$ - and $y$-axes locate the midpoint of the bicommissural line. The most rostral part of the left prefrontal cortical region is also demonstrated (see Fig. 1 for the full extent of this region). $P F C$, prefrontal cortex.

\section{Amygdala}

The second hypothesis tested held that BF in the left amygdala should also differ between depressives and controls, based upon the extensive ipsilateral interconnectivity between the prefrontal cortex and the amygdala, and the evidence that the amygdala is involved in emotional modulation. Normalized activity in the atlas-based VOI placed in the left amygdala was found to be increased in the depressed subjects, with a mean difference of $5.8 \%[t=2.60$, corrected $\mathrm{df}=13$ (Hays, 1973), $p<0.05$, two-tailed; Fig. 2].

\section{Post hoc analyses}

To determine how BF in the left prefrontal cortex and amygdala changed with remission of the depressive syndrome, radioactivity was measured in the same VOIs in the remitted group. This evidence suggests that the changes in the left prefrontal cortex represent a state abnormality. Activity in the left prefrontal cortex did not differ between the remitted and control subjects (mean difference of $-2.1 \% ; t=-1.10$; corrected $\mathrm{df}=$ 24 , NS) and was significantly reduced in the remitted subjects relative to the depressed subjects from group $\mathrm{B}$ (mean difference of $-6.1 \% ; t=-3.05$; df $=15 ; p<0.01$, two-tailed; Figs. 3, $4 A$ ). In contrast, the change in the left amygdala may represent a trait abnormality, since it was present in both depressed and remitted groups [activity did not differ between the depressed and remitted groups (mean difference of $-1.3 \% ; t=-0.441$, NS), and a trend toward increased activity was found in the remitted group relative to the control group (mean difference of $+4.9 \% ; t=1.69$; corrected $\mathrm{df}=10 ; p<0.20$, two-tailed; Fig. $4 B)$ ].

In assessing the laterality of the BF differences, a normal rightleft asymmetry emerged in the prefrontal cortex that was lost in the depressed state. Activity in the left prefrontal cortex was significantly less than in the right in both the control $(-5.0 \%$; $t=4.07 ; p<0.003$, two-tailed) and remitted subjects $(-5.0 \%$; $t=2.577 ; p<0.03$, two-tailed), but the left prefrontal cortex did not differ from the right in the depressed subjects $(+1.8 \%$; $t=0.97$, NS; Fig. 4A). Mean activity in the right prefrontal cortex did not differ between the depressed and control subjects.

A similar right-left asymmetry was not found for the amygdala. Left amygdala activity did not significantly differ from right in depressed $(+1.4 \% ; t=0.39)$, remitted $(-0.4 \%)$, or control subjects $(-0.2 \%$; Fig. $4 B)$. The mean activity in the right amygdala of the depressed group was $4.1 \%$ greater than that of the control group, but this difference was not significant $(t=$ 1.51). The comparable $4.3 \%$ difference between the remitted and control groups in the right amygdala was also not significant $(t=1.62)$.

In addition to examining the left prefrontal cortex and amygdala in the depressed as compared to the remitted state, we also inquired as to the behavior of these two areas in the depressed state relative to the degree of depression as measured by total

Figure 3. Increased activity in the left prefrontal cortex was found in the depressed subjects but not the remitted subjects. Each t-image indicates areas where subjects in the depressed (top) and remitted (bottom) phases of FPDD have increased tissue radioactivity relative to the control subjects. Mean voxel t-values for the sagittal planes from 47-57 $\mathrm{mm}$ left of the bicommissural line are demonstrated. The significance of the area of increased t-values in the left posterior temporal region of the remitted group will be explored in a future study. 

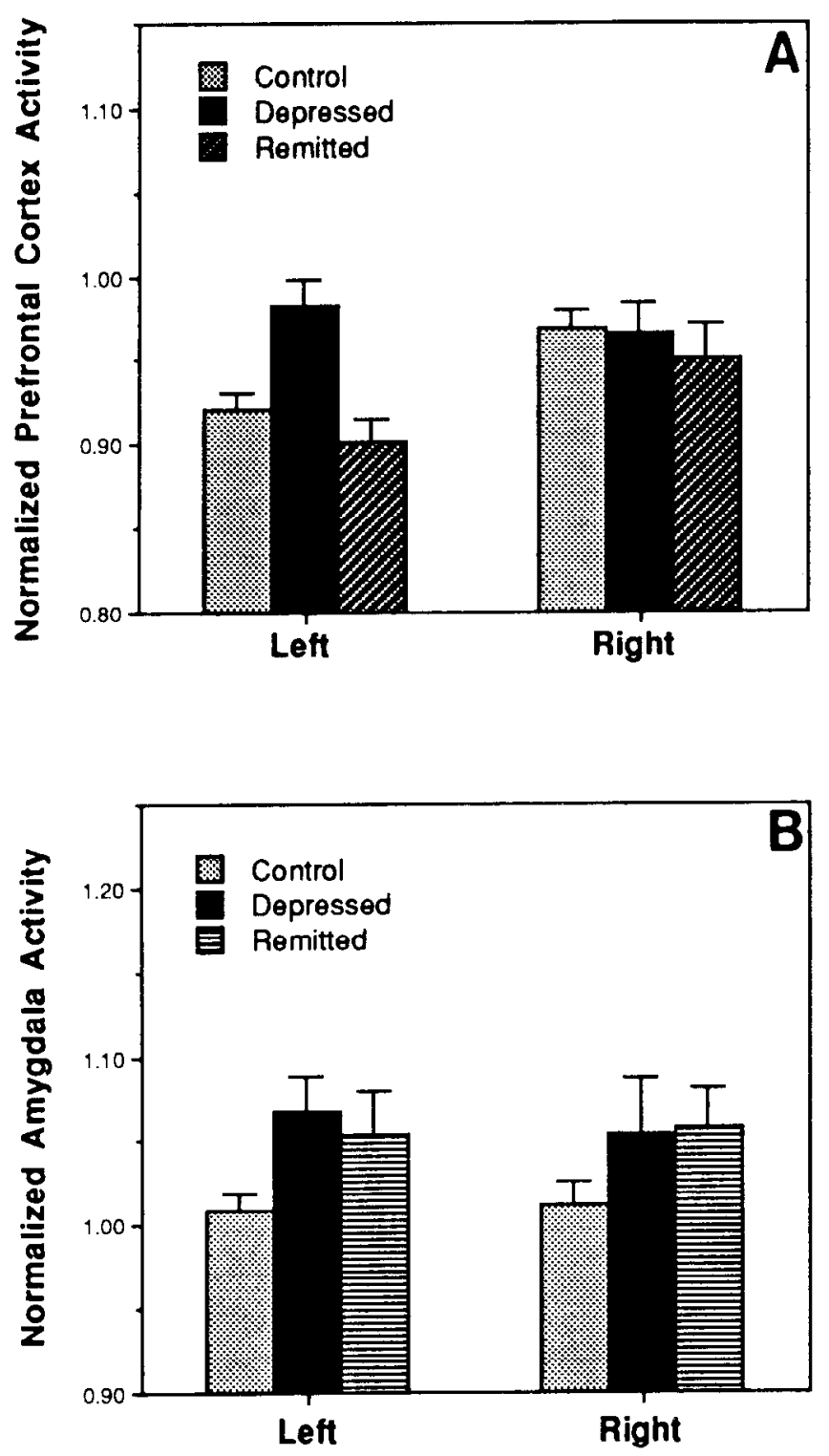

Figure 4. A, Mean activity in the left and right prefrontal cortex for control, dcpressed, and remitted groups. In the left prefrontal cortex the differences between the depressed and control groups, and between the depressed and remitted groups were significant. Differences between the left and right prefrontal cortex were significant for the control and remitted groups, but not for the depressed group. $B$, Mean activity in the left and right amygdala. In the left amygdala, the difference between the depressed and control groups was significant. Values are mean normalized tissue radioactivity (regional activity/global activity); error bars represent SEM.

HDRS scores. The relationships between radioactivity and depression severity revealed a significant positive correlation between total HDRS scores and normalized activity in the amygdala $(r=0.725 ; \mathrm{df}=7 ; p<0.05$, two-tailed; Fig. 5). In contrast, a significant negative correlation was found between total HDRS scores and activity in the left prefrontal cortex $(r=-0.619$; df $=11 ; p<0.05$, two-tailed; Fig. 5). No significant correlations were found between anxicty scores and activity for the amygdala $(r=0.045)$ or the prefrontal cortex $(r=0.319)$.

In the depressed subjects, a trend toward a negative correlation was found between regional activity in the left prefrontal cortex and the left amygdala in individual cases $(r=-0.623$;
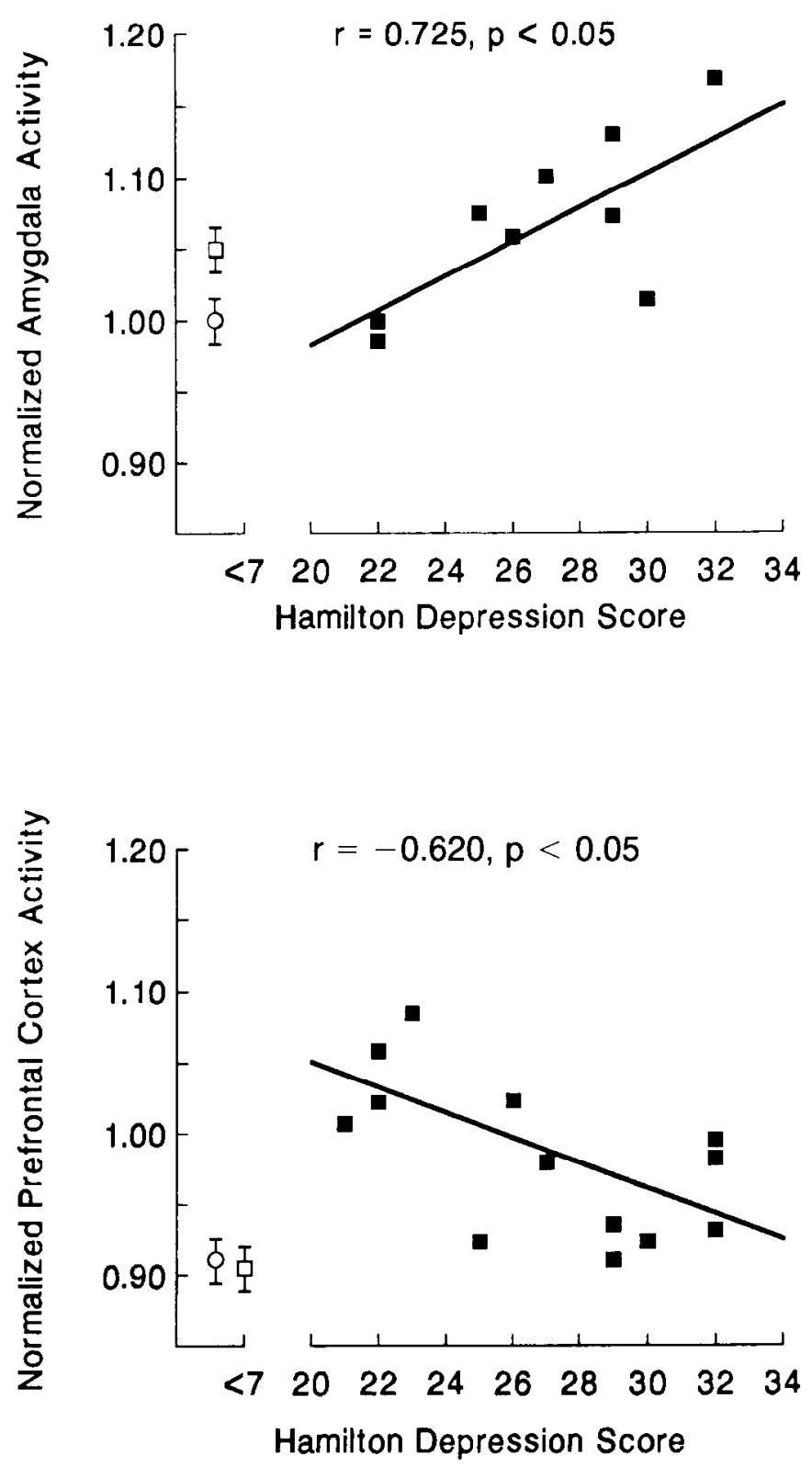

Figure 5. Regional activity versus HDRS scores for the left amygdala (top) and the left prefrontal cortex (bottom). Pearson product-moment correlation coefficients for the depressed subjects appcar above each graph. Solid squares represent individual subjects in the depressed group. The open square represents the mean of the remitted group, and the circle, the mean of the control group. Error bars for the latter two points indicate SEM. HDRS scores $<7$ are in the nondepressed range (Bech et al., 1986).

$\mathrm{df}=7 ; p<0.1$, two-tailed). In the controls, however, regional values for the amygdala did not correlate with those for the left prefrontal cortex $(r=0.020)$. No significant correlations occurred between activity in the left prefrontal cortex and age for either the depressed $(r=0.032$, NS) or the control subjects $(r$ $=0.192$, NS). Similarly, activity in the left amygdala did not correlate with age for either the depressed $(r=-0.285, \mathrm{NS})$ or the control subjects $(r=-0.118, \mathrm{NS})$.

\section{Other regions}

In considering their role in depression it is likely that the amygdala and the prefrontal cortex are part of a more extended func- 
Table 2. Regions containing greatest differences in the composite t-image generated from the entire group of depressed and control subjects

\begin{tabular}{|c|c|c|c|c|c|}
\hline \multirow[b]{2}{*}{ Region } & \multicolumn{3}{|c|}{ Coordinates $(\mathrm{mm})$} & \multirow{2}{*}{$\begin{array}{l}\text { Regional } \\
t\end{array}$} & \multirow{2}{*}{$\begin{array}{l}\% \text { Dif- } \\
\text { ference }\end{array}$} \\
\hline & $x$ & $y$ & $z$ & & \\
\hline L frontal polar $\mathrm{C}$ & 31 & 60 & 7 & 4.6 & 6.7 \\
\hline L VLPFC & 47 & 41 & 6 & 4.6 & 9.4 \\
\hline $\mathrm{L}$ medial prefrontal $\mathrm{C}$ & 7 & 55 & 6 & 3.6 & 7.0 \\
\hline $\mathrm{R}$ frontal polar $\mathrm{C}^{*}$ & -25 & 59 & 3 & 3.0 & 4.4 \\
\hline $\mathrm{R}$ putamen, claustrum, or insula* & -30 & -4 & 3 & 3.9 & 5.0 \\
\hline L amygdala & 18 & 8 & -14 & 3.6 & 8.9 \\
\hline L medial thalamus* & 5 & -7 & 2 & 3.6 & 7.2 \\
\hline $\mathrm{R}$ hippocampus or posterior thalamus* & -13 & -17 & 0 & 3.5 & 4.4 \\
\hline L occipital $C^{*}$ & 31 & -53 & 18 & -5.1 & -6.8 \\
\hline R medial temporal gyrus* & -49 & -25 & 3 & -4.7 & -6.5 \\
\hline R occipital $C^{*}$ & -23 & -48 & 13 & -3.7 & -6.0 \\
\hline $\mathrm{R}$ medial caudate* & -3 & 31 & 9 & -2.9 & -6.5 \\
\hline L medial caudate* & 8 & 25 & 16 & -2.8 & -7.1 \\
\hline
\end{tabular}

Stereotaxic coordinates (interpreted as in Table 1) locate the center of mass for the difference in tissue radioactivity within each area. The regions described in the left VLPFC, left front polar cortex, and left medial prefrontal cortex were encompassed by the prefrontal cortical VOI demonstrated in Figure $1 A$. The center of mass for the left amygdala was approximately $4 \mathrm{~mm}$ anteromedial from the center of the atlas-based region generated to measure amygdala activity (Table 1). Those regions marked by an asterisk were not included in the regions that were statistically tested. Regions where BF was decreased in the depressives relative to the controls are indicated by negative $t$-values. Percentage difference represents the mean difference in normalized tissue radioactivity between depressed and control groups for each region. $\mathbf{L}$, left; $\mathbf{R}$, right; C, cortex.

tional anatomic circuit (LeDoux, 1987; Price et al., 1987). Although additional statistical comparisons within our data set would not be justified (since corrections would reduce the significance of our findings in the amygdala and prefrontal cortex), we created a composite t-image using the entire group of depressed $(n=13)$ and control $(n=33)$ subjects to identify areas of probable BF difference that could guide hypotheses in FPDD

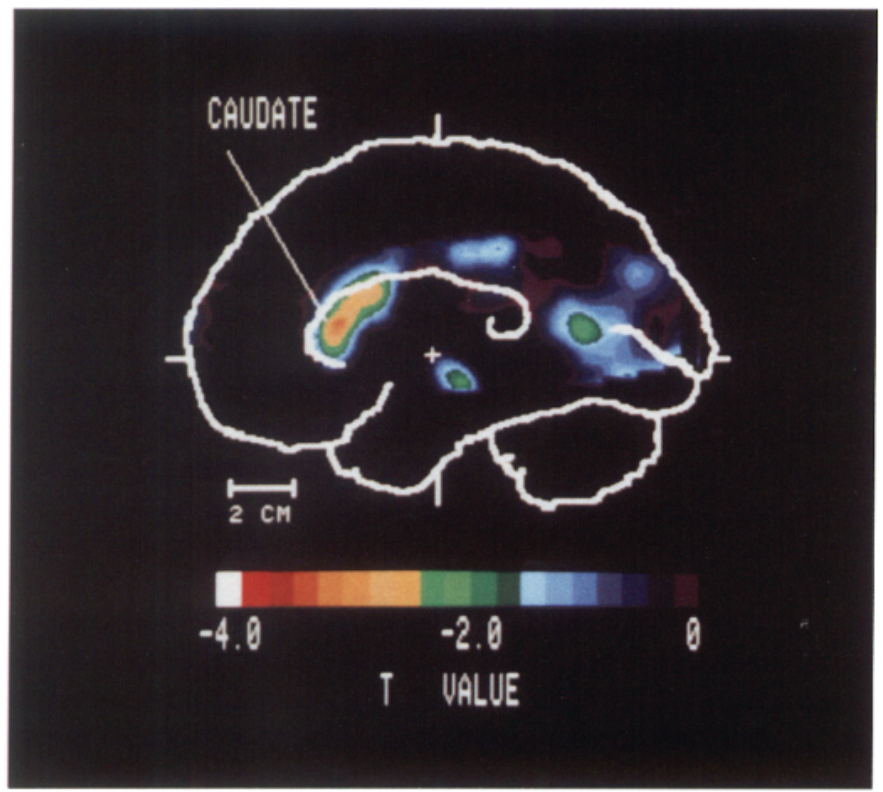

Figure 6. Decreased activity was observed in the left caudate of the depressed subjects. The t-image demonstrates areas of decreased activity in the depressives relative to the controls in a sagittal projection of the greatest voxel t-values in all planes between the midline and $10 \mathrm{~mm}$ left of midline. Anterior is to the left. The coordinates for the affected area include the head of the caudate nucleus and an arc passing posteriorly, dorsally, and laterally, suggesting that the caudate body may also be involved. The color bar is reversed to indicate negative t-values.
(Table 2; Figs. 1B,6). Regions were reported in Table 2 if power calculations indicated a greater than $50 \%$ likelihood of replication of a difference of at least $5 \%$ in a data set of identical sample size (criterion $p=0.05$ ).

In this larger group of subjects, three regions were identified within the area encompassed by the left prefrontal cortical VOI generated using subject group A (Fig. 1A). These corresponded to a lateral component involving the VLPFC, an anterior component in the frontal polar cortex, and a medial component in the pregenual portion of the anterior cingulate gyrus (Fig. $1 B$, Table 2). Approximate Brodmann areas corresponding to these regions were determined based upon comparison of their stereotaxic coordinates with human cadaver brains (by J.L.P. and S.T.C.). The left VLPFC included the caudal part of Brodmann's area 11 (comparable to Walker's area 12 in the monkey), and areas 45 and 47 (Brodmann, 1909; Walker, 1940). The frontal polar region involved area 10 (although the dorsolateral part of this region is cytoarchitectonically similar to area 46 in the monkey). The medial prefrontal region appeared to involve area 32 in the pregenual part of the cingulate gyrus. A fourth area of increased activity in the prefrontal cortex was in the right frontal polar cortex, in the part of area 10 contralateral to the area of difference in the left frontal polar cortex (Fig. 1B).

The depressed group also had three subcortical sites of increased $\mathrm{BF}$ in addition to that in the amygdala: the left medial thalamus, an area in the vicinity of the right posterolateral putamen, claustrum, or insula, and an area in the vicinity of the right hippocampal formation or posterior thalamus (Table 2). In addition, five regions corresponded to areas of decreased $\mathrm{BF}$ in the depressives relative to controls: the medial caudate bilaterally (Fig. 6), and areas in the right mid-temporal gyrus and the left and right parieto-occipital cortex.

\section{Discussion}

We obtained evidence that cerebral $\mathrm{BF}$ is increased in the left prefrontal cortex and the left amygdala in FPDD, a familial 
defined subset of unipolar major depression. In the left prefrontal cortex, BF was elevated in the depressed but not the remitted phase of FPDD. In contrast, left amygdala flow appeared increased in both phases, with significantly increased flow in the depressed relative to the control group, a trend toward increased flow in the remitted relative to the control group, and no difference between the depressed and remitted groups. These data imply that FPDD is associated with a state abnormality involving the left prefrontal cortex, and possibly with a trait abnormality involving the amygdala, though further assessment in a larger sample size is needed to confirm the latter observation.

\section{Methodologic issues}

To identify differences between depressives and controls, we implemented a two-step analysis using one set of patients and controls to define a specific VOI and a second, independent, set of patients and controls to test the hypothesis generated from the first set. This approach is to be contrasted with previous functional imaging studies of depression that relied upon regions of interest specified a priori for comparing patients and controls. The selection of regions a priori has been motivated in part by statistical considerations in dealing with the large number of independent voxels in PET images. While this approach effectively minimizes the number of statistical comparisons, it also reduces statistical power when regions are chosen for major depression, where the functional anatomy remains uncertain. Moreover, it is especially difficult to demarcate a region of interest in the cerebral cortex, where boundaries between areas are not well defined.

To improve our sensitivity in defining an area of interest, we used a t-image to reveal the greatest intergroup differences relative to each voxel's inherent variability. Variance is not uniform in composite PET images, and increases where intersubject anatomic variability is high (e.g., at brain-nonbrain boundaries). By minimizing artifacts due to nonspecific differences in anatomy, physiology, and image processing that are characterized by high variance, and enhancing subtle but consistent differences, the t-image provides an intergroup comparison image superior to a simple subtraction of summed images. The statistical significance of regional $t$-values cannot be deduced directly from this image, however, as they represent a distribution of comparisons and not single, independent samples. Hypothesis testing was thus performed in a separate group of subjects.

Testing a specific hypothesis with a separate set of patient and control images is also necessary to reduce the probability of detecting artifactual differences. Direct comparisons of composite PET images from different subjects may produce artifactual differences due to failures to compensate completely for anatomical variability with stereotaxic transformation, residual errors in image alignment, and nonuniform sampling of threedimensional space. The likelihood of such errors occurring is also reduced by employing image averaging with relatively lowresolution images from several subjects and by performing regional analysis with a large VOI.

The difference in amygdala activity was tested using an anatomically predefined VOI instead of one based on a regional t-value because several of the earlier scans used in this study did not adequately sample the ventral areas of the brain. When the amygdala became part of a working hypothesis, all scans included the amygdala. Lacking a sufficiently large sample to divide into two test groups, we chose to use this less sensitive approach. The compactness of the amygdala and its relatively well-defined anatomical boundaries aided this approach - variability was more likely to arise from inaccuracies in our image transformation scheme than from an inability to define the area of functional interest. The stereotaxic transformation algorithm we used was shown by Fox et al. (1985) to yield stereotaxic coordinates varying in location with a standard deviation of 5 $\mathrm{mm}$ or less in all three dimensions.

An important strength of our study was the selection of a relatively homogeneous subject sample using criteria for FPDD. This is the first PET investigation of a sample selected for a particular trait variable in unipolar depression, namely, family history. Such a distinction may pertain to pathophysiology, given the heritability of affective disorders (Rush et al., 1991). These criteria also enhance the likelihood of obtaining subjects with genetic purity for unipolar depression (Winokur, 1982; Rice et al., 1987; Moldin et al., 1991), a critical concern in PET studies since unipolar and bipolar depressives appear to differ in their respective circulatory and metabolic correlates (Baxter et al., 1985; Buchsbaum et al., 1986; Schwartz et al., 1987, 1989; O'Connell et al., 1989; Delvenne et al., 1990).

\section{Previous studies}

Methodologic differences between this and previous functional imaging studies of depression make direct comparison of findings across studies difficult. First, the VOI in the left prefrontal cortex that we assessed differs from the regions evaluated by other imaging groups, and other studies did not specifically evaluate the amygdala. Second, most previous studies were confounded by the failure to separate unipolar and bipolar subjects and by medication effects. Third, of the studies that did attempt to select unipolar subjects, none restricted their subjects to FPDD. Nevertheless, since FPDD is a subtype of unipolar major depression, other studies providing data for unmedicated, unipolar depressives may be comparable with ours (Baxter et al., 1985, 1987, 1989; Buchsbaum et al., 1986).

Our results in the prefrontal cortex appear partially consistent with earlier reports of increased glucose metabolism in the orbital gyri of unipolar depressives. Baxter et al. (1987) reported a bilateral increase in the orbital:hemisphere ratio of $5 \%$, which is similar in magnitude to our $\mathrm{BF}$ data (BF has been shown to correlate with glucose metabolism; Fox et al., 1988). The left prefrontal cortical region that we assessed contained a portion of the lateral orbital cortex, but extended heyond the orbital gyrus into the inferior frontal gyrus and the anterior cingulate gyrus. Similarly, Buchsbaum et al. (1986) reported increased frontal:occipital ratio, and their data suggested that this was largely due to increased ventral frontal metabolism. Decreased glucose metabolism in the left dorsal anterolateral prefrontal cortex has also been described in both unipolar (Baxter et al., 1989) and bipolar depressives [Baxter et al., 1989; Martinot et al., 1990 (although the latter study was confounded by medication effects)]. We did not find evidence of this dorsal anterolateral prefrontal difference in FPDD.

By empirically defining a VOI using inherent differences in the first half of our depressed and control subjects rather than by prespecified borders of a prefrontal "area," we may have more accurately demarcated a prefrontal cortical abnormality in unipolar depression. The regions specified a priori evaluated in previous studies may have contained portions that did not differ from controls and may not have circumscribed the entire extent of a regional abnormality. Delineating the distribution 
of a regional difference using a $\mathrm{t}$-image is particularly useful in the prefrontal cortex, where knowledge concerning the functional roles of specific areas is limited (Fuster, 1989).

Our finding that activity was increased in the left prefrontal cortex in the depressed but not the remitted phase of FPDD suggests that this abnormality constitutes a marker for the depressed state, which returns to normal with symptom remission. Although this feature has not been noted by previous investigators, it is consistent with Prohovnik et al. (1986), who found a $67 \%$ remission rate in a patient group whose mean left frontal $\mathrm{BF}$ decreased $17 \%$ following bilateral electroconvulsive therapy (ECT), and a $0 \%$ remission rate in a group whose left frontal $\mathrm{BF}$ did not decrease following unilateral ECT.

The normal asymmetry in which right prefrontal activity exceeded left in the control group (Fig. 4A) is compatible with previous data for resting, normal subjects (Gur et al., 1984; Perlmutter et al., 1987). Our finding that this prefrontal asymmetry is not present in the depressed phase of FPDD is similar to observations in medicated, unipolar depressives (Gur et al., 1984). In the remitted phase of FPDD, this normal asymmetry appears to be restored (Fig. $4 A$ ).

PET studies of unmedicated, unipolar depressives have also found reduced caudate metabolism bilaterally (Baxter et al., 1985), consistent with our observations (Fig. 6, Table 2). Notably, McDonald et al. (1990) found reduced caudate volume in depression. Their subjects were substantially older than ours, as we selected a relatively young sample in an attempt to avoid the structural abnormalities reported by their group in depressives having a late age of onset (Coffey et al., 1989; Figiel et al., 1991). However, reduced caudate size could appear as decreased BF in low-resolution PET images (Mazziotta, 1981).

The composite t-image also indicated decreased activity in the right medial temporal gyrus and in the parieto-occipital cortex bilaterally (Table 2). Decreased BF and metabolism were previously reported in these general areas in depression (Uytdenhoef et al., 1983; Post et al., 1987; Hurwitz et al., 1990). These regions are generally associated with sensory processing, and the significance of decreased BF in such areas is unclear. Dysfunction in these areas during depression had previously been hypothesized based upon neuropsychological test performance abnormalities. For example, right temporal lobe dysfunction was suggested as an explanation for the consistent finding of reduced left ear auditory sensitivity in depressed subjects (Yozawitz et al., 1979; Bruder et al., 1981; Bcrger-Gross and Bruder, 1984; Epstein, 1986). In addition, dysfunction in the temporal or occipital neocortex was hypothesized as a cause for sensory memory deficits involving modality-specific failures of preattentive information registration in depression (Sackeim and Steif, 1988). Perhaps in major depression, neural systems involved in processing exteroceptive information are inhibited in favor of systems involved in processing emotion or negative thoughts.

\section{Functional correlations}

Increased $\mathrm{BF}$ in the amygdala and the prefrontal cortex may represent either physiologic concomitants of their roles in mediating the cognitive, emotional, or behavioral symptoms of depression, or disrupted physiology associated with the primary pathophysiologic defect causing such symptoms. Although one cannot yet decide which interpretation is correct, determining the state versus trait nature of these abnormalities begins to address this question. Since the abnormality in the left prefrontal cortex appears to be a state marker, it presumably reflects the physiology underlying the expression of at least part of the depressive syndrome. In contrast, if the abnormality in the amygdala is a trait marker, it presumably represents a more fundamental aspect of the disease process and the vulnerability to major depression. The extant data regarding these structures merit comment.

The amygdala. There is considerable evidence that the amygdala plays a role in assigning affective significance to experiential stimuli (Kling, 1972; Kling and Steklis, 1976; Gloor et al., 1982; LeDoux, 1987; Neill, 1988; Nishijo et al., 1988). The amygdala receives highly processed extcroceptive input from all sensory modalities, and it has outputs both to areas of the hypothalamus and brainstem that are involved in organizing the autonomic and behavioral responses associated with emotion, and to the prefrontal cortex and other limbic-related forebrain structures (Ricardo and Koh, 1978; Turner et al., 1980; Sarter and Markowitsch, 1985; LeDoux, 1987; Price et al., 1987). Individual cells within the amygdala respond to a variety of sensory and visceral stimuli, and some of these show differential responses to aversive and rewarding stimuli (Nishijo et al., 1988). Bilateral destruction of the amygdala results in the "psychic blindness" of the Kluver-Bucy syndrome, such that the significance of stimuli cannot be recognized (Weiskrantz, 1956; Aggleton and Passingham, 1981). In addition, bursts of EEG activity have been recorded in the amygdala during recollection of specific emotional events (Halgren, 1981), and electrical stimulation of the amygdala can cvoke cmotional expcriences (especially fear or anxiety), complex hallucinations, and feelings of déjà vu (Gloor et al., 1982).

Our data suggest but do not confirm that increased $\mathrm{BF}$ in the amygdala reflects a trait abnormality in FPDD (Fig. $4 B$ ), and that the magnitude of this abnormality correlates with the severity of the depressive symptoms (Fig. 5). It is conceivable that dysfunction of the amygdala's role in evaluating affective significance could yield a state where negative affective labels are inappropriately assigned to all stimuli, resulting in depressed mood, or where positive affective labels are not assigned to any stimuli, resulting in anhedonia. Relevant to this, the amygdala has been implicated as a primary target of both the acute and chronic pharmacologic actions of antidepressant drugs (Horovitz, 1966; Gorka et al., 1979; Broekkamp and Lloyd, 1981; Duncan et al., 1986; Ordway et al., 1991).

The prefrontal cortex. The Icft prcfrontal cortical abnormality appeared to include lateral, anterior, and medial components (Fig. 1B, Table 2). The lateral component contained much of the left VLPFC, and the medial component involved the pregenual portion of the anterior cingulate gyrus. Both of these regions are interconnected with the ipsilateral amygdala (Amaral and Price, 1984).

The role of the prefrontal cortex in unipolar depression is unclear, but the experimental literature provides some clues. The prefrontal cortex contains relatively high proportions of cells that undergo sustained change in their rate of discharge during the delay period between a reward-linked sensory cue and the subsequent response to it (Fuster, 1989). In the ventral prefrontal cortex, activity following this delay period is related to the presence or absence of reward, as one type of cell appears to encode the availability of reward, and a second type, deviations from expectancy of reward (Rosenkilde et al., 1981).

Based on the results of lesions in monkeys, it has been suggested that the prefrontal cortex in general is concerned with 
the use of short-term, representational memory, such that behavior can be guided by representations of a stimulus instead of the stimulus itself (Goldman-Rakic, 1987). This would allow concepts or memories to govern behavior in the absence of informative external cues (Goldman-Rakic, 1987; Fuster, 1989). Damasio et al. (1990) reported that humans with destruction of the ventral prefrontal cortex lose the experience and expression of emotion related to thoughts that would ordinarily evoke emotion, yet have no difficulty forming plans or working intellectually through problems (however, the extent of damage in these cases involved a large part of the prefrontal cortex through gray or white matter destruction, so it is difficult to relate this syndrome directly to our findings). It may be that the ventral prefrontal cortex participates in the association of concepts held on line in representational memory with emotion and action (Collins, 1988).

Increased $\mathrm{BF}$ in distinct but overlapping portions of the left VLPFC was observed in two other experiments in our laboratory which involved psychiatrically well subjects. In the first, subjects were presented nouns (for $150 \mathrm{msec}$ ) and asked to generate related verbs (Petersen et al., 1989), while in the second subjects were asked to contemplate sad thoughts or memories (Pardo et al., 1991). A common feature of both tasks was the process of associating thoughts or emotions with a previous thought. Depressed subjects may also be engaged in a similar associative operation, as they characteristically experience incessant negative thoughts concerning personal failure, death, or interpersonal loss. All three conditions (generating verbs, contemplating sad thoughts, and depressive ruminations) involve making associations with information being held in representational memory: semantic associations in the case of the language task, and emotional associations in the case of depressive ruminations and the sad thoughts task. Consistent with the view that increased flow in the left VLPFC in depression may reflect a physiologic correlate of depressive ruminations, Perris and Monakhov (1979) found that left frontal EEG activity in depressives correlated with ruminative ideation, but not with depressed mood.

Dysfunction of the left VLPFC may also be associated with a perseverative state involving melancholic thoughts or emotions. Monkeys with surgical lesions of this region demonstrate "perseverative interference," characterized by difficulty in learning to withhold responses to nonrewarding stimuli, presumably because of interference from a strong, competing response tendency (Iversen and Mishkin, 1970). Likewise, humans with lesions of the prefrontal cortex exhibit difficulty shifting intellectual strategies in response to changing demands (i.e., they perseverate in strategies that become inappropriate; Goldman-Rakic, 1987; Fuster, 1989). It might be hypothesized that impaired modulation of the prefrontal cortex in patients with FPDD interferes with their ability to shift emotional or cognitive sets appropriately, such that they maintain a negative thought pattern or mood.

In the medial prefrontal cortex, the anterior cingulate cortex has previously been implicated in emotion. Papez (1937) hypothesized that the cingulate gyrus was the cortical receptive area for experiencing emotion, based upon observations that tumors involving the cingulate produce apathy and stupor (LeDoux, 1987). Bilateral cingulate ablation has been associated with akinetic mutism, characterized by the absence of motivation to behave or speak (Damasio and Van Hoesen, 1983). In contrast, more limited surgical lesions within the anterior

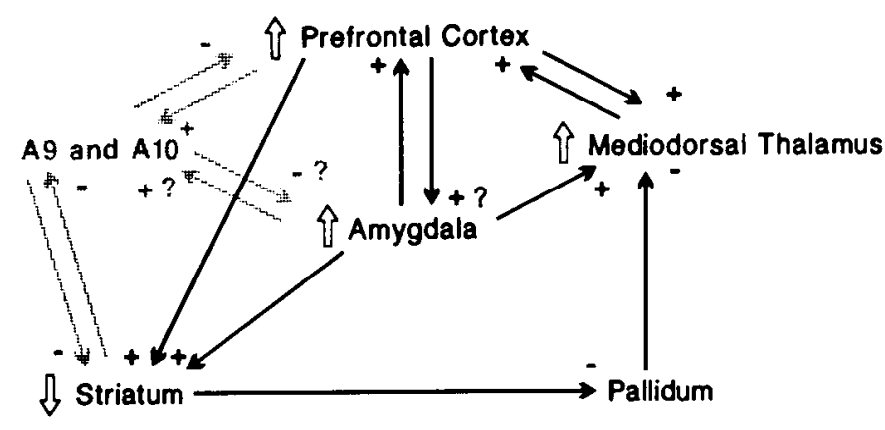

Figure 7. Neuroanatomical circuits hypothesized to participate in the functional anatomy of unipolar major depression. Regions containing BF differences have adjacent open arrows, which indicate the direction of change in flow in the depressives relative to controls. The regions' monosynaptic connections with each other are illustrated (solid arrows), with " + "indicating excitatory and "-." inhibitory projections, and with "?" indicating where experimental evidence is limited. The portions of the prefrontal cortex referred to involve primarily the ventrolateral and medial prefrontal cortex (see Results). The parts of the striatum under consideration are the ventral medial caudate and nucleus accumbens, which particularly project to the ventral pallidum (Nauta and Domesick, 1984). The major dopaminergic projections from the substantia nigra $(A 9)$ and the ventral tegmental area $(A 10)$ to these structures are illustrated with the shaded tone.

cingulate are reported to ameliorate severe depressive and anxiety syndromes (Ballantine et al., 1987). However, PET studies have thus far emphasized the role of the anterior cingulate in attention and selection for action (Petersen et al., 1989; Reiman et al., 1989; Pardo et al., 1990; Posner and Petersen, 1990; Corbetta et al., 1991).

It is likely that the functions of the cingulate gyrus differ across its approximately $15 \mathrm{~cm}$ length. Functional heterogeneity is suggested by electrical stimulation studies, which have demonstrated arousal and heightened attention, simple motor movements, or affective changes such as euphoria, anguish, sadness, or fear (Damasio and Van Hoesen, 1983), depending upon which portion of the cingulate is stimulated (Talairach et al., 1973; Laitinen, 1979). Sites of increased activity in the anterior cingulate were previously found in our laboratory during activation paradigms involving attention and language (Petersen et al., 1989; Pardo et al., 1990; Posner and Petersen, 1990; Corbetta et al., 1991), but these were located approximately $2-5 \mathrm{~cm}$ caudal and dorsal to the site of increased BF in depression (Table 2). Pcrhaps the pregenual portion of the anterior cingulate cortex (area 32 ) is more specifically involved in emotion.

\section{Correlations with depression severity}

The correlations between regional radioactivity and HDRS scores (which attempt to rate depression severity; Hamilton, 1967) suggest complex relationships between symptom severity and BF. The positive correlation between HDRS scores and activity in the amygdala together with the observation that activity in the amygdala did not differ between the depressed and remitted phases of FPDD suggests two possibilities: (1) left amygdala BF is increased in the asymptomatic phase, and further increases during a depressive episode in proportion to symptom severity; or (2) the degree of baseline dysfunction involving the amygdala determines the severity of depressive episodes.

In contrast, activity in the left prefrontal cortex correlated negatively with HDRS scores. This may relate to our hypothesis that elevated BF in the VI PFC in depression is associated with 
negative ruminations. As depression severity worsened from moderate to severe levels, negative thoughts appeared to diminish in frequency, as the severely depressed subjects commonly complained that their thinking processes had "slowed down." If BF in the VLPFC is associated with negative thinking, then the correlation between prefrontal flow and depression severity should be positive for mild depression and become negative for severe depression (Fig. 5). All of our subjects fell in the moderate to severe range. Studies involving subjects with depression ratings in the mild range are needed to test this hypothesis.

\section{Anatomical circuits related to depression}

A variety of indirect evidence has suggested that the limbic cortical-striatal-pallidal-thalamic circuit is involved in the pathophysiology of depression (Swerdlow and Koob, 1987; McHugh, 1989; Folstein et al., 1991). Our findings of increased $\mathrm{BF}$ in the amygdala and prefrontal cortex coupled with indications of increased flow in the medial thalamus and reduced flow in the medial caudate (Tables 1,2 ) more directly and specifically suggest that two interconnected circuits are involved in the pathophysiology of unipolar depression: a limbic-thalamiccortical circuit involving the amygdala, the mediodorsal nucleus of the thalamus (MD), and the ventrolateral and medial prefrontal cortex; and a limbic-striatal-pallidal-thalamic circuit involving the striatum and the ventral pallidum as well as the components of the other circuit (Fig. 7). The first of these circuits can be conceptualized as an excitatory triangular circuit whereby the amygdala and the prefrontal cortical regions are interconnected by apparently excitatory projections with each other and with MD (Porrino et al., 1981; Amaral and Price, 1984; Russchen et al., 1987; Carnes and Price, 1988; Kuroda and Price, 1991). Through these connections the amygdala is in a position both to activate the prefrontal cortex directly and to modulate the reciprocal interaction between the prefrontal cortex and MD.

The limbic-striatal-pallidal-thalamic circuit constitutes a disinhibitory sideloop between the amygdala or prefrontal cortex and MD. The amygdala and the prefrontal cortex send excitatory projections to overlapping parts of the ventromedial caudate and nucleus accumbens (Kim et al., 1977; Reubi and Cuenod, 1979; Rowlands and Roberts, 1980; Streit, 1980; Russchen et al., 1985; Selemon and Goldman-Rakic, 1985; Fuller et al., 1987). As with the more extensively studied dorsal striatalpallidal pathway, this part of the striatum sends an inhibitory projection to the ventral pallidum (Graybiel, 1990), which in turn sends GABAergic, inhibitory fibers to MD (Kuroda and Price, 1991). Because the pallidal neurons have relatively high spontaneous firing rates (DeI ong, 1972; Mink and Thach, 1991), activity in the prefrontal cortex or amygdala that activates the striatum and in turn inhibits the ventral pallidum would release MD from an inhibitory pallidal influence. Thus, if the amygdala is abnormally active in major depression, it can potentially produce an episode of abnormal activity in the prefrontal cortex and MD both directly and through the striatum and pallidum.

Swerdlow and Koob (1987) proposed a neural model for depression involving the limbic cortical-striatal-pallidal-thalamic circuit that is compatible with our data, and may additionally explain the observation of decreased BF in the caudate. Based in part upon evidence of decreased dopaminergic activity in depression (Willner, 1983; Jimerson, 1987), they hypothesized that decreased dopaminergic transmission into the ventromedial caudate and nucleus accumbens (Nauta and Domesick,
1984) enhances reverberatory activity between the prefrontal cortex, amygdala, and MD. They proposed that this leads to the perseveration of a fixed set of cortical activity manifested by the emotional, cognitive, and motor processes of depression. Dopaminergic projections from the substantia nigra and ventral tegmental area to the striatum, amygdala, and prefrontal cortex comprise an important inhibitory or modulatory input into these structures (Rowlands and Roberts, 1980; Thierry et al., 1988; Graybiel, 1990; Smith and Bolam, 1990; see Fig. 7). Thus, the effect of mesostriatal dopamine deficiency would be to increase striatal output, thereby inhibiting the pallidum and disinhibiting MD (Wooten and Collins, 1981). This, together with the decrease in direct dopamine effects in the amygdala and prefrontal cortex, would increase activity in the limbic-thalamic-cortical circuit, potentially yielding the BF increases found here (Fig. 7). Moreover, if mesostriatal dopaminergic transmission is reduced, decreased synaptic activity at striatal dopamine receptors would likely appear as decreased BF in the caudate (Brown and Wolfson, 1978; Wechsler et al., 1979; McCulloch et al., 1982; Baxter et al., 1985), also consistent with our observations (Fig. 6, Table 2).

Noradrenergic, serotonergic, and cholinergic projections into this system exist as well as the dopaminergic projections, and likely contribute to its overall modulation (Graybiel, 1990). While somatic antidepressant therapies influence each of these systems, their therapeutic mechanisms may be associated with enhancing dopaminergic (Jimerson, 1987; Osman and Potter, 1991) and serotonergic activity (especially $5-\mathrm{HT}_{1 \mathrm{~A}}$ relative to 5 $\mathrm{HT}_{2}$; Charney et al., 1990; Goldfarb, 1990; Goodwin and Jamison, 1990). Both effects would be predicted to inhibit the limbic-thalamic-cortical circuit (Meltzer and Lowy, 1987; Thierry et al., 1988; Charney et al., 1990; Goldfarb, 1990).

\section{Clinical correlations}

Lesions that involve the parts of the prefrontal cortex that participate in the limbic-thalamic-cortical circuit, and diseases of the basal ganglia (e.g., Parkinson's disease and Huntington's disease) are associated with higher rates of major depression than other similarly debilitating conditions (Mayeux, 1983; Jeste et al., 1988; Starkstein et al., 1988; Starkstein and Robinson, 1989; Folstein et al., 1991). These observations suggest that dysfunction at multiple points within this system may give rise to the major depressive syndrome. Because these conditions affect this system in different ways, it may also be suggested that imbalances within these circuits, rather than overall increased or decreased synaptic activity within a particular structure, may be associated with the major depressive syndrome (Martin et al., 1984; Rougemont et al., 1984; Young et al., 1986). It is noteworthy that most of the neurosurgical procedures that appear to ameliorate treatment-refractory depression interrupt projections within the limbic-thalamic-cortical and the limbicstriatal-pallidal-thalamic circuits (Knight, 1965, 1972; Corsellis and Jack, 1973; Nauta, 1973; Newcombe, 1975, 1982; Ballantine et al., 1987).

\section{References}

Aggleton JP, Passingham RE (1981) Syndrome produced by lesions of the amygdala in monkeys (Macaca mulatta). J Comp Physiol Psychol 95:961-977.

Amaral DG, Price JL (1984) Amygdalocortical projections in the monkey. J Comp Neurol 230:465-496.

American Psychiatric Association (1987) Diagnostic and statistical 
manual of mental disorders (DSM-III-R). Washington, DC: American Psychiatric Association.

Ballantine HT Jr, Bouckoms AJ, Thomas EK, Giriunas IE (1987) Treatment of psychiatric illness by stereotactic cingulotomy. Biol Psychiatry 22:807-819.

Baxter LR, Phelps ME, Mazziotta JC, Schwartz. JM, Gerner RH, Selin CE, Sumida RM (1985) Cerebral metabolic rates for glucose in mood disorders. Arch Gen Psychiatry 42:441.

Baxter LR, Phelps ME, Mazziotta JC, Guze BH, Schwartz JM, Selin CE (1987) Local cerebral glucose metabolic rates in obsessive-compulsive disorder-a comparison with rates in unipolar depression and in normal controls. Arch Gen Psychiatry 44:211-218.

Baxter LR, Schwartz JM, Phelps ME, Mazziota JC, Guze BH, Selin CE, Gerner RH. Sumida RM (1989) Reduction of prefrontal cortex glucose metabolism common to three types of depression. Arch Gen Psychiatry $46: 243$.

Bech P, Kastrup M, Rafaelson OJ (1986) Mini-compendium of rating scales for states of anxiety depression mania schizophrenia with corresponding DSM III syndromes. Acta Psychiatr Scand 326:1-37.

Berger-Gross P, Bruder GE (1984) Dichotic listening in the morning and evening. Int $\mathrm{J}$ Neurosci 22:277-282.

Brodmann K (1909) Vergleichende lokalisationslehre der grosshirnrinde. Leipzig: (von Johann Ambrosius) Barth.

Broekkamp CL, Lloyd KG (1981) The role of the amygdala on the action of psychotropic drugs. In: The amygdaloid complex (Ben-Ari Y, ed), pp 219-225. Amsterdam: Elsevier-North Holland Biomedical.

Brown LL, Wolfson LI (1978) Apomorphine increases glucose utilization in the substantia nigra, subthalamic and corpus striatum of rat. Brain Res 140:188-193.

Bruder G, Sutton S, Berger-Gross P, Quitkin F, Davies S (1981) Lateralized auditory processing in depression: dichotic click detection. Psychiatry Res 4:253-266.

Buchsbaum MS, Wu J, DeLisi LE, Holcomb H, Kessler R, Johnson J, King AC, Hazlett E, Langston K, Post RM (1986) Frontal cortex and basal ganglia metabolic rates assessed by positron emission tomography with $\left[{ }^{18} \mathrm{~F}\right] 2$-deoxyglucose in affective illness. J Affective Disord 10:137.

Carnes KM, Price JL (1988) Sources of presumptive glutaminergic/ aspartergic afferents to the rat mesial prefrontal cortex. Soc Neurosci Abstr 14:480.

Charney DS, Woods SW, Krystal JH, Nagy LM, Heninger GR (1990) Hypotheses relating serotonergic dysfunction to the etiology and treatment of panic and generalized anxiety disorders. In: Serotonin in major psychiatric disorders (Coccaro EF, Murphy DL, eds), pp 129 152. Washington, DC: American Psychiatric.

Coffey CE, Figiel GS, Djang WT, Saunders WB, Weiner RD (1989) White matter hyperintensity on magnetic resonance imaging: clinical and neuroanatomic correlates in the depressed elderly. J Neuropsychiatry $1: 135-144$.

Collins RC (1988) Prefrontal-limbic systems: evolving clinical concepts. In: Advances in contemporary neurology (Plum F, ed). pp 185204. Philadelphia: Davis.

Corbetta M, Miezin FM, Dobmeyer S, Shulman GL, Peterson SE (1991) Selective and divided attention during visual discriminations of shape, color, and speed: functional anatomy by positron emission tomography. J Neurosci 11:2383-2402.

Corsellis J, Jack AB (1973) Neuropathological observations on yttrium implants and on undercutting in the orbito-frontal areas of the brain. In: Surgical approaches in psychiatry, Chap 12 (Laitinen LV, Livingston KE, eds). Lancaster, UK: Medical and Technical Publishing.

Craig TJ (1986) Epidemiology of Psychiatric Illness. In: The medical basis of psychiatry (Winokur $G$, Clayton $P$, eds), pp 541-561. Philadelphia: Saunders.

Damasio AR, Van Hoesen GW (1983) Emotional disturbance associated with focal lesions of the limbic frontal lobe. In: Neuropsychology of human emotion (Heilman K, Satz P, eds), pp 85-110. New York: Guilford.

Damasio AR, Tranel D, Damasio H (1990) Individuals with sociopathic behavior caused by frontal damage fail to respond autonomically to social stimuli. Behav Brain Res 41:81-94.

DeLong MR (1972) Activity of basal ganglia neurons during movement. Brain Res 40:127-135.

Delvenne V, Delecluse F, Hubain PP, Schoutens A, deMaertelaer V, Mendlewicz J (1990) Regional cerebral blood flow in patients with affective disorders. Br J Psychiatry 157:359.

Drevets WC, Raichle ME, Fox PT, Prcskorn SH, Videen TO (1989) Trait and state cerebral blood flow abnormalities in depression. Soc Neurosci Abstr 15:30.
Duncan GE, Breese GR, Criswell H, Stumpf WE, Mueller RA, Covey JB (1986) Effects of antidepressant drugs injected into the amygdala on behavioral responses of rats in the forced swim test. J Pharmacol Exp Ther 238:758-762.

Epstein D (1986) Perceptual asymmetry in major depressive disorder: effects of electroconvulsive therapy. PhD thesis, New York University.

Figiel GS, Krishnan KRR, Doraiswamy PM, Rao VP, Nemeroff CB, Boyko OB (1991) Subcortical hyperintensities on brain magnetic resonance imaging: a comparison between late age onset and early onset elderly depressed subjects. Neurobiol Aging 26:245-247.

Folstein SE, Peyser CE, Starkstein SE, Folstein MF (1991) Subcortical triad of Huntington's disease-a model for a neuropathology of depression, dementia, and dyskinesia. In: Psychopathology and the brain (Carrol BJ, Barrett JE, eds), pp 65-75. New York: Raven.

Fox PT, Mintun MA (1989) Noninvasive functional brain mapping by change distribution analysis of averaged PET images of $\mathrm{H}_{2}{ }^{15} \mathrm{O}$ tissue activity. J Nucl Med 30:141-149.

Fox PT, Perlmutter JS, Raichle ME (1985) A stereotactic method of anatomical localization for positron emission tomography. J Comput Assist Tomogr 9:141.

Fox PT, Burton H, Raichle ME (1987) Mapping human somatosensory cortex with positron emission tomography. J Neurosurg 67:3443.

Fox PT, Raichle ME, Mintun MA. Dence C (1988) Nonoxidative glucose consumption during food physiologic neural activity. Science 241:462-464.

Fuller TA, Russchen FT, Price JL (1987) Sources of presumptive glutaminergic/aspartergic afferents to the rat ventral striatopallidal region. J Comp Neurol 258:317.

Fuster JM (1989) The prefrontal cortex-anatomy, physiology, and neuropsychology of the frontal lobe. New York: Raven.

Gloor P, Olivier A, Quesney LF, Andermann F, Horowitz S (1982) The role of the limbic system in experiential phenomena of temporal lobe epilepsy. Ann Neurol 12:129-144.

Goldfarb J (1990) Electrophysiologic studies of serotonin receptor activation. Neuropharmacology 3:435-446.

Goldman-Rakic PS (1987) Circuitry of primate prefrontal cortex and regulation of behavior by representational memory. In: Handbook of physiology - the nervous system V (Mills J, Mountcastle VB, eds), pp 373-417. Baltimore: Williams and Wilkins.

Goodwin DW, Guze SB (1984) Affective disorders. In: Psychiatric diagnosis (Goodwin DW, Guze SB, eds), pp 3-38. New York: Oxford UP.

Goodwin FK, Jamison KR, eds (1990) Manic-depressive illness. New York: Oxford UP.

Gorka Z, Ossowska K, Stach R (1979) The effect of unilateral amygdala lesion on the imipramine action in behavioural despair in rats. $\mathrm{J}$ Pharm Pharmacol 31:647-648.

Graybiel AM (1990) Neurotransmitters and neuromodulators in the basal ganglia. Trends Neurosci 13:244-254.

Gur RE, Skolnick BE, Gur RC, Caroff S, Rieger W, Obrist WD, Younkin D, Reivich M (1984) Brain function in psychiatric disorders. II. Regional cerebral blood flow in medicated unipolar depressives. Arch Gen Psychiatry 41:695-699.

Halgren E (1981) The amygdala contribution to emotion and memory: current studies in humans. In: The amygdaloid complex (Ben-Ari Y, ed), pp 395-408. Amsterdam: Elsevier-North Holland Biomedical.

Hamilton M (1960) A rating scale for depression. J Neurol Neurosurg Psychiatry 23:56-62.

Hamilton M (1967) Development of a rating scale for primary depressive illness. Br J Soc Clin Psychol 6:278-296.

Hays WL (1973) Statistics for the social sciences. New York: Holt, Rinehart and Winston.

Horovitz ZP (1966) The amygdala and depression. In: Antidepressant drugs (Garattini S, Dukes M, eds), pp 121-129. Amsterdam: Excerpta Medica.

Hurwitz TA, Clark C, Murphy E, Klonoff H, Martin WRW, Pate BD (1990) Regional cerebral glucose metabolism in major depressive disorder. Can J Psychiatry 35:684-688.

Iverson SD, Mishkin M (1970) Perseverative interference in monkeys following selective lesions of the inferior prefrontal convexity. Exp Brain Res 11:376-386.

Jeste DV, Lohr JB, Goodwin FK (1988) Neuroanatomical studies of major affective disorders - a review and suggestions for further research. Br J Psychiatry 153:444-459.

Jimerson DC (1987) Role of dopamine mechanisms in the affective 
disorders. In: Psychopharmacology: the third generation of progress (Meltzer HY, ed), pp 505-511. New York: Raven.

Kathol RG, Mutgi A, Williams J, Clamon G, Noyes R (1990) Diagnosis of major depression in cancer patients according to four sets of criteria. Am J Psychiatry 147:1021-1024.

Kim JS, Hassler R, Hong P, Paik KS (1977) Effect of frontal cortex ablation on striatal glutamic acid levels in the rat. Brain Res 132: 370-374.

Kling A (1972) Effects of amygdalectomy on social-affective behavior in non-human primates. In: The neurobiology of the amygdala (Eleftheriou BE, ed), pp 511-536. New York: Plenum.

Kling A, Steklis HD (1976) A neural substance for affiliative behavior in non-human primates. Brain Behav Evol 13:216-238.

Knight $G$ (1965) Stereotactic tractotomy in the surgical treatment of mental illness. J Neurol Neurosurg Psychiatry 28:30.

Knight GG (1972) Bifrontal stereotaxic tractotomy in the substantia innominata. In: Psychosurgery, Vol 26 (Hitchcock E, Laitinen L, Vaernet K, eds), pp 267-277. Springfield: Thomas.

Kuroda M, Price JL (1991) Synaptic organization of projections from basal forebrain structures to the mediodorsal nucleus of the rat. $J$ Comp Neurol 303:513.

Laitinen LV (1979) Emotional responses to subcortical electrical stimulation in psychiatric patients. Clin Neurol Neurosurg 81-3:148-157.

LeDoux JE (1987) Emotion. In: Handbook of physiology - the nervous system V (Mills J, Mountcastle VB, Plum F, Geiger SR, eds), pp 373417. Baltimore: Williams and Wilkins.

Lewis A (1971) 'Endogenous' and 'exogenous': a useful dichotomy? Psychol Med 1:191-196.

Martin WRW, Beckman JH, Calne DB, Adam MJ, Harrop R, Rogers JG, Ruth TJ, Sayre CI, Pate BD (1984) Cerebral glucose metabolism in Parkinson's disease. Can J Neurol Sci 11:169-173.

Martinot JL, Hardy P, Feline A, Huret JD, Mazoyer B, Attar-Levy D, Pappata S, Syrota A (1990) Left prefrontal glucose hypometabolism in the depressed state: a confirmation. Am J Psychiatry 147:13131317.

Mayeux R (1983) Emotional changes associated with basal ganglia disorders. In: Neuropsychology of human emotion (Hcilman KM, Satz P, eds), pp 141-164. New York: Guilford.

Mazziotta JC, Phelps ME, Plummer D, Kuhl DE (1981) Quantitation in positron emission computed tomography. 5. Physical-anatomical effects. J Comput Assist Tomogr 5:734-743.

McCulloch J, Savaki HE, McCulloch MC, Jehle J, Sokoloff L (1982) The distribution of alterations in energy metabolism in the rat brain produced by apomorphine. Brain Res 243:67-80.

McDonald W, Husain MH, Doraiswamy PM, Figiel GS, Boyko OB, Ellinwood EH, Nemeroff CB, Krishnan KRR (1990) Diminished caudate volumes in major depression. Paper presented at the American Psychiatric Association annual meeting, New York, NY, May.

McHugh PR (1989) The neuropsychiatry of basal ganglia disorders. Neuropsychiatr Neuropsychol Behav Neurol 2:239-247.

Meltzer HY, ed (1987) Psychopharmacology: the third generation of progress, pp 493-686. New York: Raven.

Meltzer HY, Lowy MT (1987) The serotonin hypothesis of depression. In: Psychopharmacology: the third generation of progress (Meltzer HY, ed), pp 513-526. New York: Raven.

Mink JW, Thach WT (1991) Basal ganglia and motor control. I. Nonexclusive relation of pallidal discharge to five movement modes. $J$ Neurophysiol 65:273-300.

Moldin SO, Reich T, Rice JP (1991) Current perspectives on the genetics of unipolar depression. Behav Genet 21:211-242.

Murphy GE (1986) Suicide and attempted suicide. In: The medical basis of psychiatry (Winokur G, Clayton P, eds), pp 562-579. Philadelphia: Sanders.

Nauta WJH (1973) Connections of the frontal lobe with the limbic system. In: Surgical approaches in psychiatry (Laitinen LV, Livingston KE, eds), pp 303-314. Baltimore: University Park.

Nauta WJH, Domesick V (1984) Afferent and efferent relationships of the basal ganglia. CIBA Found Symp 107:3-29.

Neill D (1988) Distinct dopamine terminal areas controlling behavioral activation and reward value of hypothalamic stimulation. In: The mesocorticolimbic dopamine system (Kalivas PW, Nemeroff CB, eds), pp 520-522. New York: The New York Academy of Sciences.

Newcombe R (1975) The lesion in stereotactic subcaudate tractotomy. Br J Psychiatry 126:478.
Newcombe R (1982) Depression and schizophrenic syndromes. In Stereotaxy of the human brain (Schaltenbrand G, Walker AE, eds), pp 591-599. New York: Thieme-Stratton.

Nishijo H, Ono T, Nishino H (1988) Single neuron responses in amygdala of alert monkey during complex sensory stimulation with affective significance. J Neurosci 8:3570-3583.

O'Connell RA, Van Heertum RL, Billick SB, Holt AR, Gonzalez A, Notardonato H, Luck D, King LN (1989) Single photon emission computed tomography (SPECT) with [123]IMP in the differential diagnosis of psychiatric disorders. J Neuropsychiatry 1:145-153.

Ordway GA, Gambarana C, Tejani-Butt SM, Areso P, Hauptmann M, Frazer A (1991) Preferential reduction of binding of 125 (super)Iiodopindolol to beta-1 adrenoceptors in the amygdala of rats after antidepressant treatments. J Pharmacol Exp Ther 257:681-690.

Osman OT, Potter WZ (1991) Potentiation of dopamine in the treatment of refractory depression. In: Refractory depression (Amsterdam JD, ed), pp 41-52. New York: Raven.

Papez JW (1937) A proposed mechanism of emotion. Arch Neural Psychiatry 79:217-224.

Pardo JV, Pardo PJ, Janer KW, Raichle ME (1990) The anterior cingulate cortex mediates processing selection in the Stroop attentional conflict paradigm. Proc Natl Acad Sci USA 87:256-259.

Pardo JV, Pardo PJ, Raichle ME (1991) Human brain activation during dysphoria. Soc Neurosci Abstr 17:664

Perlmutter JS, Powers WJ, Herscovitch P, Fox PT, Raichle ME (1987) Regional asymmetries of cerebral blood flow, blood volume, and oxygen utilization and extraction in normal subjects. J Cereb Blood Flow Metab 7:64-67.

Perris C, Monaknov K (1979) Depressive symptomatology and systemic structural analysis of the EEG. In: Hemisphere asymmetries of function in psychopathology (Gruzelier J, Flor-Henry P, eds), pp 2.23236. Amsterdam: North Holland-Elsevier.

Petersen SE, Fox PT, Posner MI, Mintun MA, Raichle ME (1989) Positron emission tomographic studies of the processing of single words. J Cogn Neurosci 1:153-170.

Porrino LJ, Crane AM, Goldman-Rakic PS (1981) Direct and indirect pathways from the amygdala to the fronlal lobe in the rhesus monkey. J Comp Neurol 198:121-136.

Posner MI, Petersen SE (1990) The attention system of the human brain. Annu Rev Neurosci 13:25-42.

Post RM, DeLisi LE, Holcomb HH, Uhde TW, Cohen R, Buchsbaum MS (1987) Glucose utilization in the temporal cortex of affectively ill patients: positron emission tomography. Biol Psychiatry 22:545553.

Price JL, Russchen FT, Amaral DG (1987) The limbic region. II: The amygdaloid complex. In: Handbook of chemical neuroanatomy, $\mathrm{V}_{\mathrm{ol}}$ 5 (Bjorklund A, Hokfelt T, Swanson LW, eds), pp 279-388. New York: Elsevier.

Prohovnik I, Sackeim HA, Decina P, Malitz S (1986) Acute reductions of regional cerebral blood flow following electroconvulsive therapy. Ann NY Acad Sci 462:249-262.

Raczkowski D, Kalat JW, Nebes R (1974) Reliability and validity of some handedness questionnaire items. Neuropsychologia 6:43-47.

Raichle ME (1987) Circulatory and metabolic correlates of brain function in normal humans. In: Handbook of physiology, Vol 5, The nervous system, Pt 2, Chap 16 (Mountcastle VB, Plum F, Geiger SR, eds), pp 643-674. Baltimore: Williams and Wilkins.

Reiman EM, Fusselman MJ, Fox PT, Raichle ME (1989) Neuroanatomical correlates of anticipatory anxiety. Science 243:1071.

Reubi JC, Cuenod M (1979) Glutamate release in vitro from corticostriatal terminals. Brain Res 176:185-188.

Ricardo JA, Koh ET (1978) Anatomical cvidence of dircet projections from the nucleus of the solitary tract to the hypothalamus, amygdala, and other forebrain structures in the rat. Brain Res 153:1-26.

Rice J, Reich T, Andreasen N, Endicott J, Van Eerdewegh M, Fishman R, Herschfeld R, Klearman G (1987) The familial transmission of bipolar illness. Arch Gen Psychiatry 44:441-447.

Robins LN, Helzer JE, Cottler L, Goldring E (1989) The Diagnostic Interview Schedule Version III-R. St. Louis: Washington University Department of Psychiatry.

Rosenkilde CE, Bauer RH, Fuster JM (1981) Single cell activity in ventral prefrontal cortex of behaving monkeys. Brain Res 209:375394

Rougemont D, Baron JC, Collard P, Bustany P, Comar D, Agid Y 
(1984) Local cerebral glucose utilisation in treated and untreated patients with Parkinson's disease. J Neurol Neurosurg Psychiatry 47: 824-830.

Rowlands GJ, Roberts PJ (1980) Specific calcium-dependent release of endogenous glutamate from rat striatum is reduced by destruction of the cortico-striatal tract. Exp Brain Res 39:239-240.

Rush JA, Cain JW, Raese J, Stewart TS, Waller DA, Debus JR (1991) Neurobiological bases for psychiatric disorders. In: Comprehensive neurology, chap 16 (Roscnberg RN, cd), pp 555-603. Ncw York: Raven.

Russchen FT, Bakst I, Amaral DG, Price JS (1985) The amygdalostriatal projections in the monkey-an anterograde tracing study. Brain Res 329:241-257.

Russchen FT, Amaral DG, Price JL (1987) The afferent input to the magnocellular division of the mediodorsal nucleus of the thalamus in the monkey, Macaca fascicularis. J Comp Neurol 256:175-210.

Sackeim HA, Steif BL (1988) Neuropsychology of depression and mania. In: Depression and mania (Georgotas A, Cancro R, eds), pp 265-289. New York: Elsevier.

Sarter M, Markowitsch HJ (1985) Involvement of the amygdala in learning and memory: a critical review, with emphasis on anatomical relations. Behav Neurosci 99:342-380.

Schatzberg AF, Samson JA, Bloomingdale KL, Orsulak PJ, Gerson B, Kizuka PP, Cole JO, Schildkraut JJ (1989) Toward a biochemical classification of depressive disorders. Arch Gen Psychiatry 46:260268.

Schwartz JM, Baxter LR, Mazziotta JC, Gerner RH, Phelps ME (1987) The differential diagnosis of depression: relevance of positron emission tomography studies of cerebral glucose metabolism to the bipolar-unipolar dichotomy. J Am Med Assoc 258:1368.

Schwartz JM, Baxter LR, Phelps ME, Mazziotta JC, Guze BH (1989) Caudate nucleus metabolism with respect to specific cortical regions discriminates bipolar depressed, unipolar depressed, and normal control populations. In: Annual meeting of the American College of Neuropsychopharmacology, p 197. Nashville, TN: American College of Neuropsychopharmacology.

Schwenk TL, Coyne JC (1990) Depression. In: Practice of family medicine, Pt VI (Rakel R, ed), pp 1582-1594. Edinburgh, Scotland: Livingstone.

Selemon LD, Goldman-Rakic PS (1985) Longitudinal topography and interdigitation of corticostriatal projection in the rhesus monkey. J Neurosci 5:776-794.

Smith AD, Bolam JP (1990) The neural network of the basal ganglia as revealed by the study of synaptic connections of identified neurones. Trends Neurosci 13:259-265.

Starkstein SE, Robinson RG (1989) Affective disorders and cerebral vascular disease. $\mathrm{Br} \mathrm{J}$ Psychiatry 154:170-182.

Starkstein SE, Robinson RG, Berthier ML, Parikh RM, Price TR (1988) Differential mood changes following basal ganglia vs thalamic lesions. Arch Neurol 45:725.

Streit $P$ (1980) Selective retrograde labelling indicating the transmitter of neuronal pathways. J Comp Neurol 191:429-463.
Swerdlow NR, Koob GF (1987) Dopamine, schizophrenia, mania and depression: toward a unified hypothesis of cortico-striato-pallido-thalamic function. Behav Brain Sci 10:197-245.

Talairach J, Szikla G, Tournoux P, Prosalentis A, Bordas-Ferrer M, Covello L, Iacob M, Mempel E (1967) Atlas d'anatomie stereotaxique du télencéphale. Paris: Masson.

Talairach J, Bancaud J, Geier S, Bordas-Ferrer M, Bonis A, Szikla G, Rusu M (1973) The cingulate gyrus and human behaviour. Electroencephalogr Clin Neurophysiol 34:45-52.

Thierry AM, Mantz J, Milla C, Glowinski J (1988) Influence of the mesocortical/prefrontal dopamine neurons on their target cells. In: The mesocorticolimbic dopamine system (Kalivas PW, Nemeroff CB, eds), pp 101-111. New York: The New York Academy of Sciences.

Turner BH, Mishkin M, Knapp M (1980) Organization of the amygdalopetal projections from modality - specific cortical association areas in the monkey. J Comp Neurol 191:515-543.

Uytdenhoef P, Portelange P, Jacquy J, Charles G, Linkowski P, Mendlewicz (1983) Regional cerebral blood flow and lateralized hemispheric dysfunction in depression. Br J Psychiatry 143:128-132.

Walker AE (1940) A cytoarchitectural study of the prefrontal area of the macaque monkey. J Comp Neurol 73:59-86.

Wechsler LR, Savaki HE, Sokoloff L (1979) Effects of $d$ - and l-amphetaminc on local ccrcbral glucose utilization in the conscious rat. J Neurochem 32:15-22.

Weiskrantz L (1956) Behavioral changes associated with ablation of the amygdaloid complex in monkeys. J Comp Physiol Psychol 49: 381-391.

Willner P (1983) Dopamine and depression: a review of recent evidence. I. Empirical studies. Brain Res Rev 6:211-224.

Winokur $G$ (1982) The development and validity of familial subtypes in primary unipolar depression. Pharmacopsychiatry 15:142-146.

Winokur G (1986) Unipolar depression. In: The medical basis of psychiatry, chap 5 (Winokur G, Clayton P, eds), pp 60-79. Philadelphia: Saunders.

Wooten GF, Collins RC (1981) Metabolic effects of unilateral lesion of the substantia nigra. J Neurosci 1:285-291.

Yamamoto M, Ficke DC, Ter-Pogossian MM (1982) Performance study of Pett VI, a positron computed tomograph with 288 cesium fluoride detectors. IEEE Trans Nucl Sci 29:529-533.

Young AB, Penney JB, Starosta-Rubinstein S, Markel DS, Berent S, Giordani B, Ehrenkaufer R, Jewett D, Hichwa R (1986) PET scan investigations of Huntington's disease: cerebral metabolic correlates of neurological features and functional decline. Ann Neurol 20:296303.

Yozawitz A, Bruder G, Sutton S, Sharpe L, Gurland B, Fleiss J, Costa L (1979) Dichotic perception: evidence for right hemisphere dysfunction in affective psychosis. Br J Psychiatry 135:224-37.

Zimmerman M, Coryell WH, Black DW (1990) Variability in the application of contemporary diagnostic criteria: endogenous depression as an example. Am J Psychiatry 147:1173-1179. 